\title{
On-line monitoring of oxygen as a method to qualify the oxygen consumption rate of wines
}

\author{
Ignacio Nevares ${ }^{1, a}$, Victor Martínez-Martínez ${ }^{1, a}$, Ana Martínez-Gil ${ }^{2, a}$, Roberto Martín ${ }^{a}$, \\ V. Felipe Laurie ${ }^{3}$, María del Álamo-Sanza ${ }^{2, a *}$ \\ ${ }^{1}$ Departamento de Ingeniería Agrícola y Forestal, Universidad de Valladolid, Spain \\ ${ }^{2}$ Departamento de Química Analítica, Universidad de Valladolid, Spain \\ ${ }^{3}$ Facultad de Ciencias Agrarias, Universidad de Talca, Chile \\ ${ }^{a}$ Grupo UVaMOX, E.T.S. Ingenierías Agrarias, Universidad de Valladolid, Spain \\ delalamo@qa.uva.es
}

\begin{abstract}
Measuring the oxygen content during winemaking and bottle storage has become increasingly popular due to its impact on the sensory quality and longevity of wines. Nevertheless, only a few attempts to describe the kinetics of oxygen consumption based on the chemical composition of wines have been published. Therefore, this study proposes firstly a new fitting approach describing oxygen consuming kinetics and secondly the use of an Artificial Neural Network approach to describe and compare the oxygen avidity of wines according to their basic chemical composition (i.e. the content of ethanol, titratable acidity, total sulfur dioxide, total phenolics, iron and copper). The results showed no significant differences in the oxygen consumption rate between white and red wines, and allowed the sorting of the wines studied according to their oxygen consumption rate.
\end{abstract}

Keywords: Wine, oxygen, oxidation, oxygen consumption rate, phenol, sulfur dioxide, iron, Artificial Neural Networks 


\section{Introduction}

Oxygen is ever-present during all phases of the winemaking process (Calderón, Alamo-Sanza, Nevares, \& Laurie, 2014), contributing to important chemical changes that affect the sensorial characteristics and the aging capacity of wines (del Alamo-Sanza, Pando, \& Nevares, 2014; Oliveira, Silva Ferreira, De Freitas, \& Silva, 2011). Oxygen is required for a sound alcoholic fermentation, color stabilization, reduction of the astringent and bitter characters, etc. (Holm Hansen, Nissen, Sommer, Nielsen, \& Arneborg, 2001; Schmidtke, Clark, \& Scollary, 2011). However, an excess of oxygen could lead to microbiological spoilage and oxidation reactions that could negatively affect the wine's color, flavor and aging capacity (Escudero, Asensio, Cacho, \& Ferreira, 2002; Laurie, Salazar, Campos, Cáceres-Mella, \& Peña-Neira, 2014; Schmidtke et al., 2011). The nonenzymatic oxidation process is thought to begin with the activation of oxygen by metal catalyzers, and the oxidation of phenols into quinones with the concomitant reduction of oxygen into hydrogen peroxide $\left(\mathrm{H}_{2} \mathrm{O}_{2}\right)$. The resulting species can further react with other wine molecules and produce sensory changes associated with wine oxidation, such as the production of acetaldehyde (Elias, Andersen, Skibsted, \& Waterhouse, 2009; Kreitman, Laurie, \& Elias, 2013; Laurie, Zuñiga, Carrasco-Sanchez, Cañete, Olea-Azar, Ugliano \& Agosin, 2012). During this process, important chemical compounds are affected, including phenols (Danilewicz, 2003, 2007; du Toit, Marais, Pretorius, \& du Toit, 2006; Kondrashov, Ševčík, Benáková, Koštírová, \& Štípek, 2009; Laurie et al., 2014; Mulero, Pardo, \& Zafrilla, 2010; Oliveira, Knapic, \& Pereira, 2012; Vrček, Bojić, Žuntar, Mendaš, \& Medić-Šarić, 2011; Zúñiga, Pérez-Roa, Olea-Azar, Laurie, \& Agosin, 2014), sulfur dioxide (Danilewicz, 2003, 2007, 2014; Zúñiga et al., 2014), ethanol (Danilewicz, 2014), ascorbic acid, glutathione. etc (Du Toit, Lisjak, Marais, \& Du Toit, 2006).

Various authors have evaluated the influence of oxygen in wine via antioxidant capacity measurements (Kondrashov et al., 2009; Mulero et al., 2010; Vrček et al., 2011), which could serve as a rough estimate of the wine's affinity towards oxygen consumption (Mulero et al., 2010). Other studies have measured the redox potential of the wine as an indication of its oxidation state (Danilewicz, 2003; Del Alamo, Nevares, \& Cárcel, 2006; Kilmartin \& Zou, 2001). In both cases, the wine matrix complexity and the errors associated have limited the chances of finding a good methodology to predict or classify wines according to their oxidation potential. Other studies evaluated the chemical changes in red wines subjected to saturation cycles with the result that the first cycle affects wine the most (Carrascon, Fernandez-Zurbano, Bueno, \& Ferreira, 2015; Ferreira, Carrascon, Bueno, Ugliano, \& Fernandez-Zurbano, 2015). The reactivity and consumption of oxygen during wine oxidation depends on chemical composition and the conservation temperature of the wine. Moutounet indicated that a red wine saturated with air consumed its dissolved oxygen in 25 hours at $13{ }^{\circ} \mathrm{C}$, while it only takes 3 hours at a temperature of $30{ }^{\circ} \mathrm{C}$ (Moutounet \& Mazauric, 2001).

This paper studied the oxygen consumption patterns of red and white real wines, and compared the accepted model of oxygen consumption with a new model fitting to approximate the kinetics of oxygen consumption. By means of an Artificial Neural Networks (ANNs) model, based on the basic chemical composition of these wines, we have defined an index capable of comparing wine oxidation rates. 


\section{Materials and Methods}

\subsection{Wine samples}

The alcohol degree (AD) was measured using a distillation method; titratable acidity (TA), $\mathrm{pH}$, volatile acidity (VA) were measured using a potentiometric method; total sulfur dioxide (free and combined $\mathrm{SO}_{2}$ ) according to an iodometric method and iron (Fe) and copper $(\mathrm{Cu})$ using an FAAS external calibration with standards in hidroalcoholic solution (13\%). These components were analyzed for a set of 32 real wines (RW) (16 reds, RRW +16 whites, WRW) following European methods (CEE, 1990). Also, the content of total phenols (TP) was measured using the Folin-Ciocalteu method as described by Singleton and Rossi (Singleton \& Rossi, 1965) (Table 1).

Another set of model wines or training wines (TW) (54 reds, RTW and 54 whites, WTW) were prepared with ultrapure water and varying concentrations of six substances closely linked with the wine's redox chemistry (Danilewicz, Seccombe, \& Whelan, 2008; Zúñiga et al., 2014) and easily measureable in a winery setting (i.e. alcohol content, titratable acidity, sulfur dioxide, total phenolics, iron and copper, as further explained below). Ethanol $(96 \% \mathrm{v} / \mathrm{v}), \mathrm{L}(+)$-Tartaric acid $(99.7-100.5 \%)$ and sodium hydrogen sulfite $(40 \% \mathrm{w} / \mathrm{v})$ were acquired from Panreac (Barcelona, Spain), whilst iron standard solution (iron III nitrate nonahydrate in nitric acid $0.5 \mathrm{~mol} / \mathrm{L}, 1000 \mathrm{mg} / \mathrm{L}$ ), and copper standard solution (copper II nitrate in nitric acid $0.5 \mathrm{~mol} / \mathrm{L}, 1000 \mathrm{mg} / \mathrm{L}$ ) were purchased from Scharlab (Barcelona, Spain). Gallic acid (97.5-102.5\%), and $(+)$ Catechin hydrate (98\%) were obtained from Sigma-Aldrich (San Luis, Missouri, USA). The concentrations of the compounds present in the training wines were as follows: Red training wines, AD (\% vol): 13, 14, and 15; TA (gTH $/ 2$ L): 4.5, 5.25 and 6; $\mathrm{SO}_{2} \mathrm{~T}(\mathrm{mg} / \mathrm{L}): 30,50$ and 70; Fe $(\mathrm{mg} / \mathrm{L}): 0.5,4$ and 8; $\mathrm{Cu}(\mathrm{mg} / \mathrm{L}): 0.03,0.4$ and 0.8; and TP (mg GAE/L): 2000, 3000 and 4000. For white training wines, the concentrations chosen were as follows: Alcohol (\% vol): 11.5, 12.5 and 13.5; TA (gTH$/ 2 / L): 4.5,5.25$ and 6; $\mathrm{SO}_{2} \mathrm{~T}(\mathrm{mg} / \mathrm{L}): 30,75$ and 100; $\mathrm{Fe}(\mathrm{mg} / \mathrm{L}): 0.5,3$ and 6; $\mathrm{Cu}(\mathrm{mg} / \mathrm{L}): 0.03,0.4$ and 0.8; and TP (mg GAE/L): 200, 300 and 400. In order to reduce the number of possible combinations in a statistically reliable fashion, the Box-Behnken factorial design (Box \& Behnken, 1960) was used, resulting in 54 combinations for each type of training or model wine (red and white) (Table 1, supplementary material).

The chemical parameters used were chosen based on some of the following considerations: Ethanol is the second most abundant compound in wines which, in addition to assisting in the dissolution of many compounds, including most of the wine phenolics, is one of the main substrates of oxidation after the phenolics (Danilewicz, 2014; Elias et al., 2009; Elias \& Waterhouse, 2010). Organic acids such as tartaric acid are known substrates of oxidation (Clark, Prenzler, \& Scollary, 2003; Danilewicz, 2014) which could be easily estimated by measuring total acidity, and contribute to the wine's $\mathrm{pH}$ and redox potential. In general, low $\mathrm{pH}$ imposes restrictions on oxidation (Danilewicz, 2007; Del Álamo et al., 2006; Oliveira et al., 2011), whilst a higher pH favors oxidation reactions (Danilewicz, 2003). Sulfur dioxide acts as one of the major antioxidant agents of wine by reacting with the $\mathrm{H}_{2} \mathrm{O}_{2}$ formed during phenol oxidation (Danilewicz, 2007), thus contributing significantly to the antioxidant capacity of wines, particularly whites (Abramovič, Košmerl, Poklar Ulrih, \& Cigić, 2015; Danilewicz, 2007). Iron and copper stand out due to their influence as catalysers of oxidation reactions and their contribution 
Table 1.- Chemical composition of the wines tested (i.e. 16 white and 16 red wines) and correlation results between OCRI and given chemical parameter.

\begin{tabular}{|c|c|c|c|c|c|c|c|c|c|c|c|c|}
\hline Wine & OCRI & $\begin{array}{c}\mathrm{Fe} \\
(\mathrm{mg} / \mathrm{L})\end{array}$ & $\begin{array}{c}\mathrm{Cu} \\
(\mathrm{mg} / \mathrm{L})\end{array}$ & $\mathrm{Fe} / \mathrm{Cu}$ & $\begin{array}{l}\mathrm{AD} \\
(\%)\end{array}$ & $\begin{array}{c}\text { TA } \\
(\mathrm{mg} / \mathrm{L})\end{array}$ & $\begin{array}{l}\text { SO2 T } \\
(\mathrm{mg} / \mathrm{L})\end{array}$ & $\begin{array}{c}\mathrm{SO2F} \\
(\mathrm{mg} / \mathrm{L})\end{array}$ & $\begin{array}{c}\text { SO2C } \\
(\mathrm{mg} / \mathrm{L})\end{array}$ & $\begin{array}{c}\text { TP } \\
(\mathrm{mg} / \mathrm{L})\end{array}$ & pH & $\begin{array}{c}\text { Vol Ac } \\
(\mathrm{g} / \mathrm{L})\end{array}$ \\
\hline & \multicolumn{12}{|c|}{ White Real Wines } \\
\hline 8 & 41.41 & 0.70 & 0.03 & 23.33 & 13.20 & 5.10 & 83 & 39 & 44 & 350 & 3.36 & 0.30 \\
\hline 4 & 42.99 & 0.30 & 0.05 & 6.00 & 12.10 & 5.20 & 64 & 32 & 32 & 228 & 3.31 & 0.24 \\
\hline 16 & 49.17 & 1.00 & 0.45 & 2.22 & 13.70 & 6.00 & 107 & 24 & 83 & 250 & 3.12 & 0.42 \\
\hline 9 & 50.73 & 0.80 & 0.48 & 1.67 & 13.40 & 5.80 & 117 & 27 & 90 & 249 & 3.20 & 0.28 \\
\hline 12 & 51.57 & 1.40 & 0.08 & 17.50 & 12.80 & 5.60 & 96 & 32 & 64 & 234 & 3.11 & 0.31 \\
\hline 2 & 51.69 & 0.80 & 0.11 & 7.27 & 12.60 & 5.50 & 119 & 20 & 99 & 245 & 3.48 & 0.16 \\
\hline 7 & 51.70 & 0.80 & 0.28 & 2.86 & 13.20 & 5.70 & 112 & 40 & 72 & 288 & 3.29 & 0.29 \\
\hline 14 & 51.90 & 1.30 & 0.08 & 16.25 & 12.80 & 5.50 & 80 & 31 & 49 & 253 & 3.11 & 0.40 \\
\hline 15 & 52.09 & 1.40 & 0.08 & 17.50 & 12.80 & 5.50 & 84 & 32 & 52 & 223 & 3.12 & 0.28 \\
\hline 3 & 53.15 & 1.20 & 0.05 & 24.00 & 12.50 & 5.30 & 104 & 32 & 72 & 288 & 3.13 & 0.38 \\
\hline 1 & 55.28 & 0.70 & 0.06 & 11.67 & 13.80 & 6.10 & 98 & 19 & 79 & 363 & 3.14 & 0.51 \\
\hline 5 & 56.10 & 1.50 & 0.05 & 30.00 & 12.70 & 5.30 & 98 & 24 & 74 & 258 & 3.11 & 0.29 \\
\hline 11 & 60.00 & 4.10 & 0.11 & 37.27 & 12.60 & 5.50 & 79 & 29 & 50 & 236 & 3.21 & 0.23 \\
\hline 6 & 60.21 & 0.80 & 0.14 & 5.71 & 13.40 & 5.40 & 113 & 37 & 76 & 333 & 3.31 & 0.27 \\
\hline 10 & 62.33 & 0.90 & 0.58 & 1.55 & 13.60 & 5.40 & 85 & 26 & 59 & 278 & 3.01 & 0.47 \\
\hline 13 & 62.53 & 1.10 & 0.09 & 12.22 & 13.30 & 5.30 & 101 & 36 & 65 & 218 & 3.34 & 0.39 \\
\hline Average & 53.30 & 1.18 & 0.17 & 13.56 & 13.03 & 5.51 & 96.25 & 30.00 & 66.25 & 268 & 3.21 & 0.33 \\
\hline Correlation & & 0.3969 & 0.1911 & 0.0764 & 0.2989 & 0.0692 & 0.2211 & -0.1390 & 0.2445 & -0.0677 & -0.2517 & 0.2755 \\
\hline$p$ level & & 0.1279 & 0.4783 & 0.7786 & 0.2608 & 0.7990 & 0.4105 & 0.6077 & 0.3615 & 0.8031 & 0.3471 & 0.3018 \\
\hline Wine & \multicolumn{12}{|c|}{ Red Real Wines } \\
\hline 8 & 39.05 & 0.70 & 0.06 & 11.67 & 14.70 & 5.30 & 36 & 30 & 6 & 2933 & 3.46 & 0.37 \\
\hline 16 & 39.99 & 1.40 & 0.06 & 23.33 & 14.10 & 5.20 & 37 & 16 & 21 & 2906 & 3.63 & 0.47 \\
\hline 13 & 40.97 & 1.40 & 0.05 & 28.00 & 14.00 & 5.20 & 32 & 13 & 19 & 2579 & 3.63 & 0.47 \\
\hline 4 & 43.25 & 1.80 & 0.17 & 10.59 & 14.50 & 4.70 & 64 & 42 & 22 & 3456 & 3.76 & 0.41 \\
\hline 1 & 44.72 & 2.40 & 0.17 & 14.12 & 13.90 & 5.20 & 53 & 27 & 26 & 3497 & 3.65 & 0.35 \\
\hline 11 & 45.22 & 1.80 & 0.13 & 13.85 & 13.30 & 5.00 & 24 & 21 & 3 & 2383 & 3.59 & 0.47 \\
\hline 9 & 47.00 & 0.80 & 0.22 & 3.64 & 13.70 & 4.60 & 45 & 19 & 26 & 2624 & 3.89 & 0.45 \\
\hline 10 & 49.40 & 1.80 & 0.13 & 13.85 & 13.20 & 4.70 & 18 & 10 & 8 & 2056 & 3.73 & 0.41 \\
\hline 7 & 49.73 & 2.50 & 0.15 & 16.67 & 14.00 & 4.80 & 70 & 40 & 30 & 3483 & 3.72 & 0.37 \\
\hline 6 & 50.90 & 2.80 & 0.14 & 20.00 & 14.10 & 4.70 & 64 & 37 & 27 & 3288 & 3.80 & 0.40 \\
\hline 15 & 53.57 & 1.20 & 0.11 & 10.91 & 13.10 & 3.90 & 19 & 8 & 11 & 1865 & 3.65 & 0.46 \\
\hline 14 & 58.39 & 1.60 & 0.38 & 4.21 & 14.10 & 4.10 & 31 & 16 & 15 & 2410 & 3.89 & 0.48 \\
\hline 12 & 61.19 & 1.80 & 0.11 & 16.36 & 12.30 & 4.40 & 59 & 33 & 26 & 2401 & 3.85 & 0.63 \\
\hline 3 & 63.50 & 2.50 & 0.17 & 14.71 & 13.90 & 4.60 & 69 & 31 & 38 & 2920 & 3.56 & 0.70 \\
\hline 5 & 64.04 & 2.50 & 0.17 & 14.71 & 13.90 & 4.60 & 69 & 39 & 30 & 2892 & 3.68 & 0.59 \\
\hline 2 & 67.32 & 1.60 & 0.62 & 2.58 & 14.00 & 4.70 & 29 & 18 & 11 & 2460 & 3.74 & 0.46 \\
\hline Average & 51.14 & 1.79 & 0.18 & 13.70 & 13.80 & 4.73 & 44.94 & 25.00 & 19.94 & 2760 & 3.70 & 0.47 \\
\hline correlation & & 0.3771 & 0.6134 & -0.3992 & -0.3380 & -0.6344 & 0.2231 & 0.1161 & 0.2090 & -0.2706 & 0.3271 & 0.6498 \\
\hline$p$ level & & 0.1499 & $0.0115 *$ & 0.1256 & 0.2005 & $0.0083 * *$ & 0.406 & 0.6685 & 0.274 & 0.3108 & 0.2126 & $0.0064 * *$ \\
\hline
\end{tabular}


between 0.093 and 0.273 showed a statistically significant and positive correlation with the copper content of the real white wines $(r=0.5922, p=0.0157)$. In all cases, a good fit was found for all wines studied with adjusted R-Sq values between 0.989 and 0.999 . Therefore, as with the proposed model, the copper content of the wine is the parameter most closely related to oxygen consumption to the wine's antioxidant capacity (Danilewicz, 2007; Oliveira et al., 2011; Zúñiga et al., 2014). Finally, wine phenolic compounds have a direct influence on wine oxidation, being the main reactants of activated oxygen in solution. As such they are an important contributor to antioxidant capacity (del Alamo-Sanza et al., 2014; Escudero et al., 2002; Holm Hansen et al., 2001; . Oliveira et al., 2011)

\subsection{Air saturation of wines}

Each of the wines (32 RW and $108 \mathrm{TW}$ ) was saturated with atmospheric oxygen using an air press pump (Selecta, Spain) that allowed the sparging of air into the liquid. Air dissolution stopped when the partial pressure of oxygen in the wine was the same as that of the atmosphere (i.e. $100 \%$ air saturation, equivalent to a concentration of approximately $7 \mathrm{mg} / \mathrm{L}$ of oxygen in water at $\mathrm{P}_{\mathrm{atm}} 1013 \mathrm{hPa}$ and $35^{\circ} \mathrm{C}$ ). The atmospheric pressure was measured using a digital barometer with an accuracy of $\pm 0.3 \mathrm{hPa}$ at $20^{\circ} \mathrm{C}$ (PTB110, Vaisala Oyj, Finland). To prevent oversaturation of oxygen in solution, highspeed air flow (i.e. air flow rates greater than $1 \mathrm{~mL} / \mathrm{min}$ ) and very small bubbles were avoided, using a procedure described elsewhere (Näykki, Jalukse, Helm, \& Leito, 2013). After saturating the wines, the dissolved oxygen content (DO) of the samples were measured every 100 seconds during 60 hours, as explained below. The data with values above 100\% (associated with an oversaturation) were discarded at the time of the statistical treatment. Then, the oxygen depletion from $100 \%$ of air sat. until a value of $5 \%$ of air saturation was evaluated.

\subsection{Measurement of DO and kinetics of oxygen consumption}

The oxygen-saturated wines were transferred onto $20 \mathrm{~mL}$ respiration vials with integrated optical oxygen sensors for DO measurements (OXVIAL20, PyroScience $\mathrm{GmbH}$, Aachen, Germany) which are airtight. The sensors are stripes of oxygen sensitive redflash-indicators glued to the inner wall of the vials [resolution: $0.01 \% \mathrm{O}_{2}(0.005 \mathrm{mg} / \mathrm{L})$ at $1 \% \mathrm{O}_{2}, 0.05 \% \mathrm{O}_{2}(0.025 \mathrm{mg} / \mathrm{L})$ at $20 \% \mathrm{O}_{2}$; Accuracy: $\pm 0.02 \% \mathrm{O}_{2}(0.01 \mathrm{mg} / \mathrm{L})$ at $1 \%$ $\mathrm{O}_{2}$ or $\pm 0.2 \% \mathrm{O}_{2}(0.1 \mathrm{mg} / \mathrm{L})$ at $\left.20 \% \mathrm{O}_{2}\right]$, which allow DO readings by means of eight optical fibers connected to a two FireStingO 2 4-channels optical oxygen meters (PyroScience GmbH, Aachen, Germany). All of the assays were performed in groups of eight vials simultaneously. The samples were kept in a thermostatic bath at a constant temperature of $35 \pm 0.01^{\circ} \mathrm{C}$ (Julabo FP40-ME, Seelbach, Germany). The oxygen sensors of each vial were calibrated according to the manufacturers' protocol, with measurements performed at two calibration points: oxygen-free water $(0 \%$ air saturation) and airsaturated water (100\% air saturation). Measurements were performed in ultrapure water in saturation conditions according to ISO 5814:2012 (International Standard Organization, 2012) and in an oxygen-free water at a concentration of $0 \mathrm{mg} / \mathrm{L}$. The $0 \%$ calibration standard was prepared based on a strong reductant; in this case, sodium dithionite $\left(\mathrm{Na}_{2} \mathrm{~S}_{2} \mathrm{O}_{4}\right)$ (Panreac, Barcelona, Spain) at a concentration of $30 \mathrm{~g} / \mathrm{L}$. 
All oxygen-measuring equipment had a temperature probe, pressure transducer, and humidity sensors used for temperature, pressure and humidity compensation. The corresponding temperature probes were introduced in the thermostatic bath, independently from the luminescence equipment as to have other means of correcting the measured values and ensuring the quality of the measurements. Similarly, the atmospheric pressure of the oxygen meter was checked with the digital barometer during every assay.

As suggested before, the testing of wines was carried out under the same temperature conditions, by keeping the samples in a high accuracy thermostatic bath at $35^{\circ} \mathrm{C}$ in darkness. All of the wines (140 real and model samples) were exposed to air until saturation, and the kinetics of oxygen depletion was measured following the concentration of DO.

\subsection{Artificial Neural Networks}

Finally, an ANN model was built for the categorization of the wines according to their oxygen consumption rate. This model was trained by correlating the chemical data and the oxygen consumption curves of the 108 model wines, and tested using the 32 real white and red wines, as further explained below. Due to the wine matrix complexity and the multiplicity of chemical compounds linked with the wine's antioxidant capacity (Zúñiga et al., 2014), is that several ANN were proposed in order to categorize the oxygen consumption rate of the wine on the basis of its basic chemical composition. The multilayer perceptron ANN used in this work presents 7 input variables (input layer, Figure 1 supplementary) of each network: a binary variable indicating whether the wine is red or white and the six chosen chemical parameters of the wines (i.e. A\%, TA, SO2T, $\mathrm{Fe}, \mathrm{Cu}$, and TP). The output variable (output layer, Figure 1 supplementary) of each ANN was a numeric-type variable that represents the wine's oxygen consumption rate and was used to compare wines with different rates. Both the input and output variables were normalized so that the mean of each variable is zero and the standard deviation is one.

The training of each ANN, employed to adjust the weight and offset values of the neurons, was done using the data acquired from the 108 model wines. Here, the back propagation algorithm based on the Levenberg-Marquardt method implemented with the trainlm function of Matlab ${ }^{\circledR}$ was employed (Hagan \& Menhaj, 1994). The minimum value of the gradient was adjusted to $10^{-15}$, and $20 \%$ of the samples were used for model validation. The process of training was conducted by varying the number of neurons included in the hidden layer of the ANN between two and 20, and replicating each of them 200 times in order to minimize the influence of the random neural network initialization of the ANN in the final outcome of the training.

\subsection{Statistical analysis}

MATLAB software was employed to implement the consumption kinetic models and the ANNs, both MATLAB ${ }^{\circledR}$ and Microsoft Excel (2016), were used to perform the correlation and error analyses. STATGRAPHICS was employed for the ANalysis Of VAriance (ANOVA) tests shown in this work. 


\section{Results and discussion}

\subsection{Kinetics of oxygen consumption}

All of the wines (140 real and model samples) were exposed to air until saturation, and the kinetics of oxygen depletion was measured following the concentration of DO. Figure 1 is a graph showing the results of monitoring the oxygen consumption of the training white wines together with the two real white wines which presented limit tendencies (Figure 1A); the results of monitoring the oxygen consumption of the real white wines together with the two training ones which presented limit tendencies are also shown (Figure 1B). The results indicate that only three (WRW4, WRW9 and WRW10) real white wines fall outside the tendencies of the training wines. In the case of the red wines.
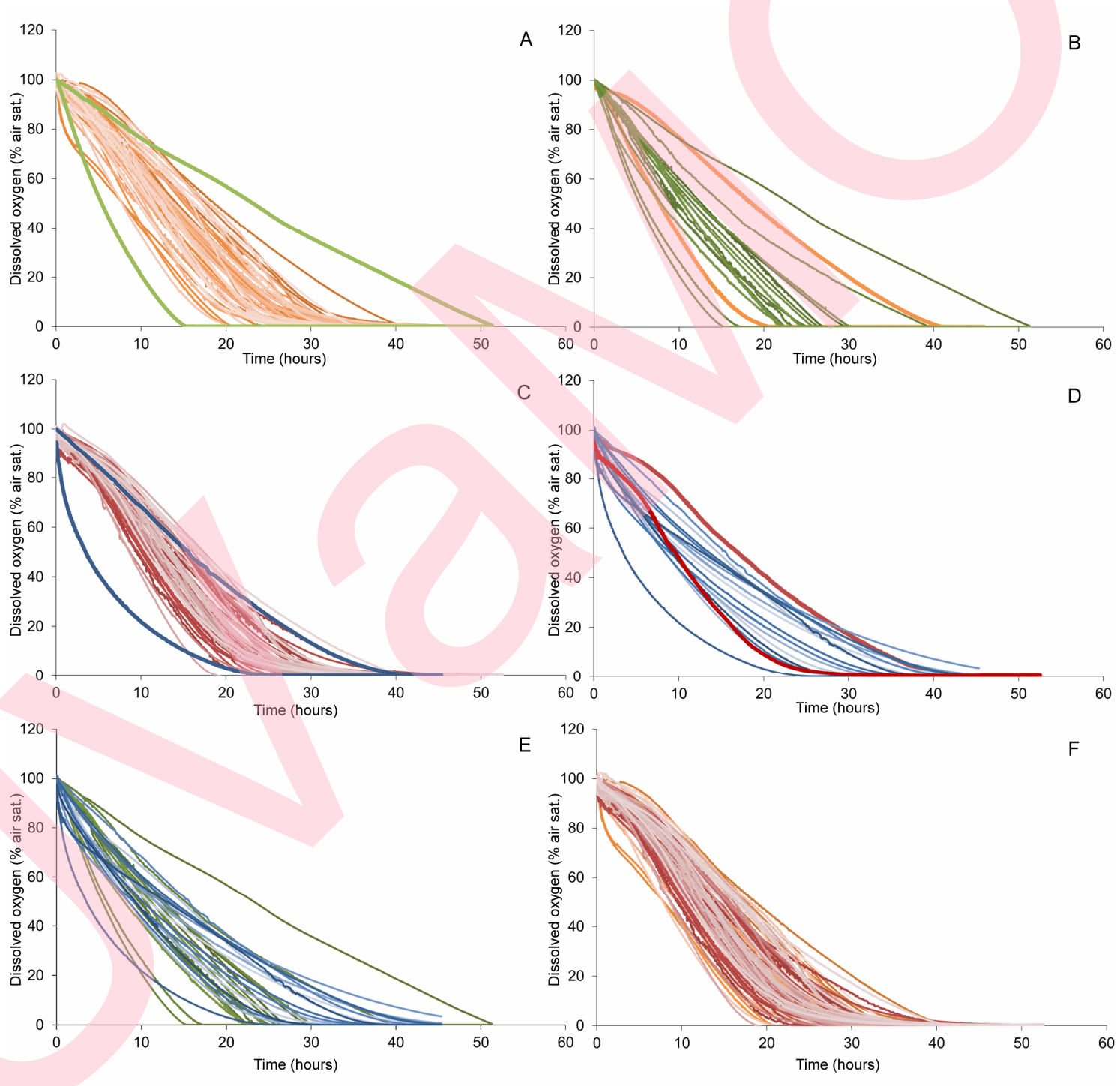

Figure 1: Oxygen kinetics of: a) model white wines (orange) and extremely real white wines (green), b) real white wines and extremely model white wines, c) model red wines (red) and extremely real red wines (blue), d) real red wines and extremely model red wines, e) real red and white wines, and f) all studied model wines. 
Figure $1 \mathrm{C}$ shows the training red wines together with the two reds which presented the most extreme tendencies, and the tendencies of the red wines together with the two model reds presenting the most different tendencies are shown in Figure 1D, indicating that only one of the real wines studied (RRW14) follows a different kinetic to the training ones. To date, it has been established that red wines can consume more oxygen than whites (Danilewicz, 2015; Kreitman, Danilewicz, Jeffery, \& Elias, 2016; Moutounet \& Mazauric, 2001; V. Singleton, 1987), however, the kinetics of oxygen consumption between the two have not been well established. In this case, the analyses of the model and white and red real wines show that both types do not have significantly different kinetics of oxygen consumption, and that they were different to those reported by Moutounet \& Mazauric (2001) and widely accepted in the sector. These differences may be due to the measuring conditions, such as temperature, the measurement system and the fact that this was not done in a closed environment (Moutounet \& Mazauric, 2001). Dr. Danilewicz used a Clarke-type electrode to perform readings at ambient temperature (20 $-25^{\circ} \mathrm{C}$ ) and the system was not completely closed during the measurements. In our case, continuous oxygen readings with a photoluminescence detector at $35^{\circ} \mathrm{C}$ were collected, and this was carried out in a perfectly airtight environment.

Oxygen consumption occurs via multiple pathways and/or reactions, but mathematically, some authors consider that $\mathrm{O}_{2}$ is consumed following a first-order reaction kinetics $\mathrm{C}=\mathrm{C}_{0} \cdot \exp (\mathrm{kt})$, where its apparent kinetic rate is an average value of all oxidation reactions occurring in wine during storage at any given temperature (Costa Martins, Monforte, \& Silva Ferreira, 2013; Oliveira, Barros, Silva Ferreira, \& Silva, 2015), therefore the following equation could be used:

$$
\left[\mathrm{O}_{2}\right](\mathrm{t})=\left[\mathrm{O}_{2}\right]_{0} \cdot \exp \left(-\mathrm{kapp}_{\mathrm{ap}} \mathrm{t}\right)
$$

where $\left[\mathrm{O}_{2}\right]_{0}$ is the initial oxygen concentration $(\mathrm{mg} / \mathrm{L})$ and $\mathrm{k}_{\text {app }}(1 /$ day $)$ is the apparent kinetic rate at the given time $(\mathrm{t})$ in days. Considering that $\mathrm{k}_{\text {app }}$ may follow the Arrhenius behavior with temperature (Costa Martins et al., 2013; Oliveira et al., 2015; Palacios Macías, Caro Pina, \& Pérez Rodríguez, 2001), the reactions were conducted at $35^{\circ} \mathrm{C}$ allowing the samples to consume the oxygen in shorter periods of $60 \mathrm{~h}$ instead of much longer times reported elsewhere (Singleton, 1987). In order to ensure a common oxygen interval for the 140 wines tested, that was representative of each kinetic pattern, the data was shortened between $85 \%$ and $5 \%$ of air sat., allowing an equation to be established that represents that specific interval for all the wines studied. The results presented in Table 2, obtained with eq. 1, show that the best fit was obtained for the real red wines (adjusted R-Sq $=0.976$ ). Similarly, the correlation between Kapp and the chemical parameters that differentiate the real wines presented in Table 1 were evaluated. More specifically, Kapp was significantly and positively correlated only with the copper content of real white (Pearson correlation coefficient $r=0.7816, p=0.0003$ ) and red wines $(r=0.7185, p=0.0017)$ (Table 2 supplementary material), indicating that at higher copper content there would be a greater initial speed of oxygen consumption.

A study of the other adjustments to represent the oxygen consumption rate indicates that oxygen consumption in the 140 wines studied has a better fit with the phenomenological trend described in equation (2). 


$$
O 2(t)=\frac{a}{1+b \cdot e^{c \cdot t}} \text { with } a>0, b>0 \text { and } c>0
$$

These results with values of parameter a between 88,347 and 143,651 showed a positive and statistically significant correlation with the copper content of the real red wines $(\mathrm{r}=$ $0.7544, \mathrm{p}=0.0007$ ) (Table 2 , supplementary material). In a similar manner, the $\mathbf{b}$ values, between 0.036 and 0.528 , showed a statistically significant and positive correlation with the copper content of the real red wines $(r=0.7542, p=0.0003)$. Similarly, the $\mathbf{c}$ values

Table 2.- Summary of the fit of the equation to the different kinetics of the 140 wines and error results. (A) exponential equation and (B) phenomenological equation.

\begin{tabular}{|c|c|c|c|c|c|c|c|}
\hline & & & WTW & WRW & RTW & RRW & Average \\
\hline \multirow{9}{*}{ 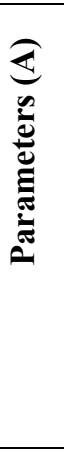 } & \multirow{3}{*}{$\mathrm{k}$} & Max & $3.3781 \mathrm{E}-05$ & $4.3873 \mathrm{E}-05$ & $3.453 \mathrm{E}-05$ & $3.983 \mathrm{E}-05$ & $3.8003 \mathrm{E}-05$ \\
\hline & & Mean & $2.2557 \mathrm{E}-05$ & $2.476 \mathrm{E}-05$ & $2.3386 \mathrm{E}-05$ & $2.0528 \mathrm{E}-05$ & $2.2808 \mathrm{E}-05$ \\
\hline & & Min & $2.1406 \mathrm{E}-05$ & $1.0712 \mathrm{E}-05$ & $1.6961 \mathrm{E}-05$ & $1.4319 \mathrm{E}-05$ & $1.585 \mathrm{E}-05$ \\
\hline & \multirow{4}{*}{$\mathrm{R}^{2}$} & Max & 0.976 & 0.971 & 0.983 & 0.993 & 0.981 \\
\hline & & Mean & 0.938 & 0.963 & 0.939 & 0.976 & 0.954 \\
\hline & & Min & 0.875 & 0.943 & 0.889 & 0.935 & 0.911 \\
\hline & & RMSE & 5.9495 & 4.3501 & 6.062 & 3.3789 & 5.5163 \\
\hline & \multirow{2}{*}{ error } & MAE & 5.2484 & 3.6965 & 5.4318 & 2.9032 & 4.8738 \\
\hline & & MxAE & 10.9709 & 10.26 & 10.1228 & 6.9526 & 10.1033 \\
\hline \multirow{15}{*}{ 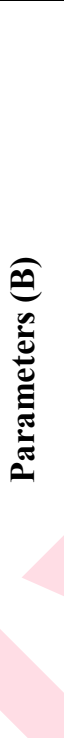 } & \multirow{4}{*}{$\mathrm{a}$} & Max & 129.9 & 135.1 & 150.6 & 151.328 & 143.651 \\
\hline & & Mean & 99.63 & 111.829 & 103.978 & 126.185 & 110.406 \\
\hline & & Min & 83.4 & 97.272 & 87.269 & 90.393 & 88.347 \\
\hline & & Max & 0.261 & 0.398 & 0.605 & 0.689 & 0.528 \\
\hline & \multirow[t]{3}{*}{$\mathrm{b}$} & Mean & 0.095 & 0.214 & 0.135 & 0.35 & 0.199 \\
\hline & & Min & 0.307 & 0.085 & 0.022 & 0.063 & 0.036 \\
\hline & & Max & 0.307 & 0.276 & 0.298 & 0.063 & 0.273 \\
\hline & \multirow[t]{3}{*}{$\mathrm{c}$} & Mean & 0.2 & 0.178 & 0.201 & 0.178 & 0.176 \\
\hline & & Min & 0.124 & 0.091 & 0.094 & 0.124 & 0.093 \\
\hline & & Max & 0.999 & 0.997 & 1 & 0.999 & 0.999 \\
\hline & \multirow[t]{3}{*}{$\mathrm{R}^{2}$} & Mean & 0.997 & 0.996 & 0.998 & 0.997 & 0.997 \\
\hline & & Min & 0.983 & 0.994 & 0.991 & 0.991 & 0.989 \\
\hline & & RMSE & 1.2870 & 1.4530 & 0.9919 & 1.1288 & 1.1741 \\
\hline & \multirow[t]{2}{*}{ error } & MAE & 1.0799 & 1.1839 & 0.8406 & 0.9442 & 0.9839 \\
\hline & & MxAE & 3.4586 & 4.3788 & 2.5435 & 3 & 3.2195 \\
\hline
\end{tabular}

RMSE (Root mean square error), MAE (mean absolute error), MxAE (maximum absolute error)

The comparative study of both adjustments for all the wines studied indicates that the phenomenological method fits the real data more significantly than the exponential equation. As an example the wines best adjusted to the exponential model (WRW9 and RRW14) were chosen and the consumption kinetics and adjustments made with both methods have been shown (Figure $2 \mathrm{~A}-\mathrm{B}$ ). It can be seen that the exponential method is only better adjusted at the start of the kinetics, with the proposed method being better $p$ level $<0.01$ for every error 

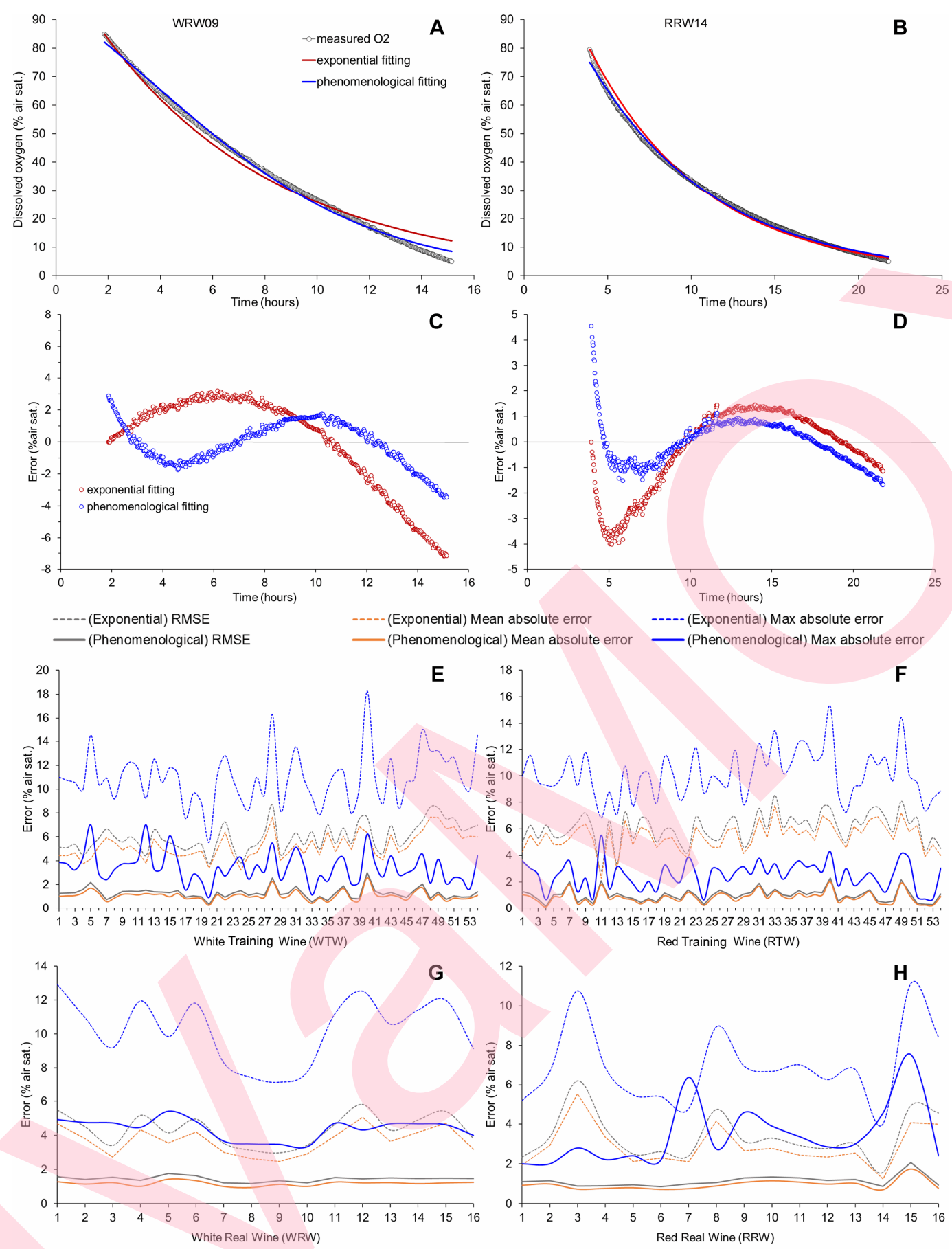

Figure 2.- Decrease in oxygen consumption in two real wines (WRW09 and RRW14) and decrease according to exponential adjustment (A) and the proposed method (B). Graphical representation of the errors MSE (Root mean square error), MAE (mean absolute error), MxAE (maximun absolute error) of each real and training wine studied.

adjusted to all the kinetic, as shown by the residuals graph (Figure $2 \mathrm{C}-\mathrm{D}$ ). The analysis of variance of the statistics of both adjustments $\left(\mathrm{R}^{2}\right.$, RSMS, mean absolute error, max absolute error Table 2) performed for all the wines and for each of the 4 types of wine separately (training and real white and red wines) indicates that the $\mathrm{R}^{2}$ of the proposed adjustment in equation 2 is significantly higher than the $\mathrm{R}^{2}$ of the exponential model. It 
has also been found that the error made is significantly greater in all the studied wines with the exponential method (Figure $2 \mathrm{E}-\mathrm{H})$.

Oxygen consumption kinetics shown in Figure 1 can be represented with a function like that presented in Figure 3. There are several statistical parameters extracted from this function or from its derivative function that can describe it, and therefore describe the oxygen consumption kinetics. In this article, three parameters were analyzed to describe this function because of their relationship with the wines' oxygen consumption capacity. The first of these parameters, hereinafter referred to as feature 1 , is defined as the time in which the DO of the wine falls from full saturation to $50 \%$ air saturation, and its value in hours was named $t_{1}$ (Eq. 3). The second parameter, which will be referred as feature 2, corresponds to the time in which the mathematical integral of the function contained half of the total area under the function, and its value in hours will be named $t_{2}$ (Eq. 4). Finally, the third parameter calculated, hereinafter referred as feature 3 , represents the time in which the integral of the rate of oxygen consumption curve contained half of its total area, and its value in hours will be named $t_{3}$ (Eq. 5). Thus, a wine with high avidity to consume oxygen will show low times $t_{1}, t_{2}$ and $t_{3}$. These three parameters $\left(t_{1}, t_{2}\right.$, and $\left.t_{3}\right)$ are represented in Figure 3, where $I_{2}$ and $I_{3}$ represent half of the total area under the oxygen consumption curve and its derivative function, respectively. The mathematical representations of these three parameters are as follows:

$$
\begin{aligned}
& \boldsymbol{t}_{\mathbf{1}} \text { so that } \boldsymbol{f}\left(\boldsymbol{t}_{\mathbf{1}}\right)=\mathbf{5 0} \% \\
& t_{2} \text { so that } I_{2}=\int_{0}^{t_{2}} f(\tau) d \tau=\frac{1}{2} \cdot \int_{0}^{\infty} f(\tau) d \tau \\
& \boldsymbol{t}_{\mathbf{3}} \text { so that } \boldsymbol{I}_{\mathbf{3}}=\int_{\mathbf{0}}^{t_{3}} \boldsymbol{f}^{\prime}(\tau) d \tau=\frac{1}{2} \int_{0}^{\infty} \boldsymbol{f}^{\prime}(\tau) d \tau
\end{aligned}
$$

where $f(t)$ is the evolution curve of DO over time and $f^{\prime}(t)$ its derivative function.

As seen in Figure 1, not all of the wines were fully capable of consuming the oxygen provided during saturation (particularly reds), showing an asymptotic pattern at DO levels below 5\% air sat. The prior serves as an indication of the importance of analyzing the data through the calculation of different parameters. For instance, feature 1 gives greater weight to the oxygen that remains in the wine, while feature 3 offers an indication of the total oxygen consumed, with feature 2 being a descriptive value of the dissolved oxygen evolution curve.

The linear correlation between each the chemical characteristics of the wine $(\% \mathrm{AD}$, $\mathrm{TA}, \mathrm{SO}_{2}, \mathrm{Fe}, \mathrm{Cu}, \mathrm{TP}$, and a variable indicating whether the wine is white or red (W/R)) and the three features used to describe the wines' oxygen consumption velocity $\left(t_{1}, t_{2}\right.$ and $\left.t_{3}\right)$ were calculated. The Pearson correlation coefficient results were $-0,1604^{+}, 0,0636$, $0.0478,-0.2677^{* *},-0.3077^{* * *},-0.2099^{*}$, and $-0.2022^{*}$, respectively, for feature 1 , $0.0811,-0.1008,-0,1189,-0.3211^{* * *},-0.3863^{* * *},-0.0551$, and -0.0265 , respectively, for feature 2 , and $-0.0475,0.0287,-0.1703^{*},-0.2500^{* *},-0.2869^{* * *},-0.0620$, and -0.0363 , respectively, for feature 3 , where ${ }^{+},{ }^{*}, * *, * * *$ indicate $\mathrm{p}<0.1, \mathrm{p}<0.05, \mathrm{p}<0.01$ and $\mathrm{p}<0.001$, respectively. In all cases, the individual significant correlations between these wine characteristics and the features chosen to describe the wine's oxygen consumption rate were, in absolute value, between 0.20 and 0.39 for feature 2, with $\mathrm{Cu}$ and $\mathrm{Fe}$ being the highest. These correlation results expose the relationship between the chemical characteristics of the wine analyzed and the oxygen consumption features proposed in the 
article. Because of these correlation results, it would be desirable to build a black-box model to relate these seven characteristics and the three features chosen in order to improve the predicting capabilities by combining the information contained on each characteristic. To this end, an ANN-based model was created to estimate the selected features and to qualify wines by their oxygen consumption rate, using simple chemical compositional parameters commonly used in wineries.

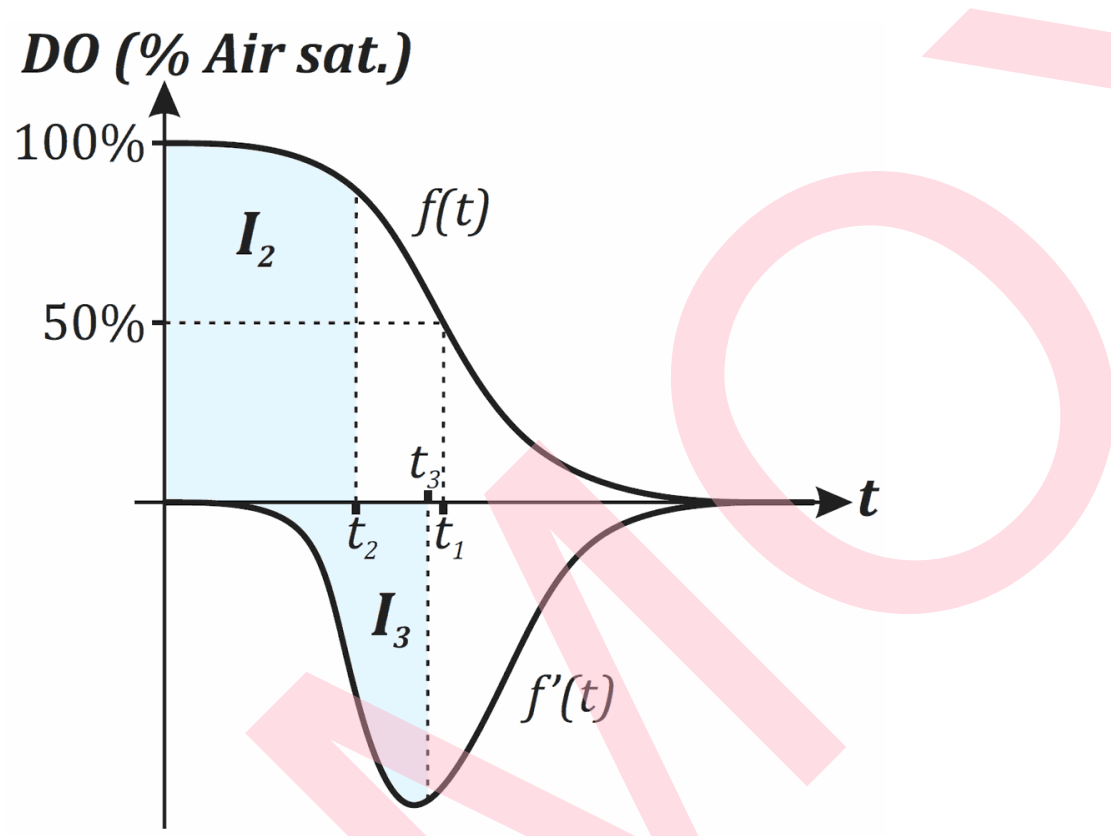

Figure 3.- Graphical representation of the oxygen consumption curve $f(t)$, its derivative function $f^{\prime}(t)$, and the three features used to describe the wines' oxygen consumption capacity $\left(t_{1}, t_{2}\right.$, and $t_{3}$ ), where $I_{2}$ and $I_{3}$ represent half of the total area under the oxygen consumption curve and its derivative function, respectively.

\subsection{Results of the neural networks}

Three ANNs were created to estimate each one of the three oxygen consumption features $\left(t_{1}, t_{2}, t_{3}\right)$ considered based on simple chemical compositional parameters commonly used in wineries. Initially, the training process of the ANNs was carried out in order to adjust the weights of each neuron of the network, and to choose the optimal number of hidden neurons. The number of neurons in the hidden layer for the ANN associated with each feature was chosen as the one with the lowest validation error, being eight hidden neurons for feature 1, and four hidden neurons for features 2 and 3. Once trained, the three neural networks were tested with the optimal number of neurons in each case, using the data obtained from the real wines.

Considering that the results obtained for each of the three features are not comparable $(t$, $t_{2}$, and $t_{3}$ varied for all the 140 wines between 2.89 and 23.19 hours for $t_{1}$, between 3.69 and 14.31 hours for $t_{2}$, and between 3.82 and 22.54 hours for $t_{3}$ ), we have proposed an index to describe the oxygen consumption rate, called Oxygen Consumption Rate Index (OCRI). OCRI is a dimensionless variable that ranges between 0 and 100, taking values close to 0 when the oxygen consumption rate of the wine is low and values close to 100 
when the oxygen consumption rate is high. Equation 6 shows the mathematical procedure to transform each feature into its corresponding OCRI:

$$
\operatorname{OCRI}_{i}(\%)=100 \cdot\left(1-\frac{t_{i}-T_{i, m i n}}{T_{i, m a x}-T_{i, m i n}}\right), i \in\{1,2,3\} \quad \text { (eq. 6) }
$$

where: $T_{i, \min }$ is 0 for the three characteristics considered $(i \in\{1,2,3\})$, describing the extreme case of a wine with the highest oxygen consumption rate, and $T_{i, \max }$ is the maximum value of $t_{i}$ for each characteristic $(i \in\{1,2,3\})$.

The mean absolute error, that is, the mean value of the absolute value of the difference between the value estimated by the ANN and the expected value, was employed to analyze the performance of the proposed ANN. Thus, the mean absolute error results for OCRI obtained using the first feature were $9.30 \%$ for the training wines, and $17.34 \%$ for the real wines, respectively. The second feature showed OCRIs with a mean absolute error of $7.04 \%$ for the training wines, and $17.29 \%$ for the real wines. The mean error results of OCRI obtained with the third feature were $7.55 \%$ for the training wines and $18.72 \%$ for the real ones. From these results, it can be observed that the lower average absolute error was obtained for the second feature, for both training and real wines. Additionally, given the results obtained for the training samples and the learning ability of neural networks, it is possible to think that the data would improve if the ANNs are trained with a larger database that includes more real wines.

The graphical representation of the results obtained with the ANN of feature 2 is shown in Figure 4. This plot represent the OCRI measured against the OCRI estimated for feature 2, distinguishing red and white wines. Feature 2 showed the cloud of points with the best distribution along the reference line, suggesting that it is possible that the data would be a good indicator of the avidity of these wines to consume oxygen. In the case of the white wines the correlation between measured and estimated OCRI was found to be 0.4807 and was 0.5177 for red wines, showing high significance in both cases $(\mathrm{p}<0.001)$. In addition to that, the results presented previously about the correlation between oxygen consumption features and wine composition show that the highest correlation between some of the chemical compounds of the wines (particularly Fe and $\mathrm{Cu}$ ) and the ANNs created were observed for feature 2. According to these results, $t_{2}$ was chosen as the best feature for the classification of the wines studied, based on its smaller error of estimation considering the OCRI, presented in the previous paragraph. As indicated previously, $t_{2}$ is defined as the time in which the area under the oxygen consumption curve from $t=0$ to $t=t_{2}$ reaches $50 \%$ of the total area under the curve of airsaturated wines conserved at $35{ }^{\circ} \mathrm{C}$ (equation (4). It is reasonable to think that this parameter $\left(t_{2}\right)$ should be small for wines with a great avidity for oxygen (i.e. wines with substances of greater reducing capacity or higher antioxidant capacity). 


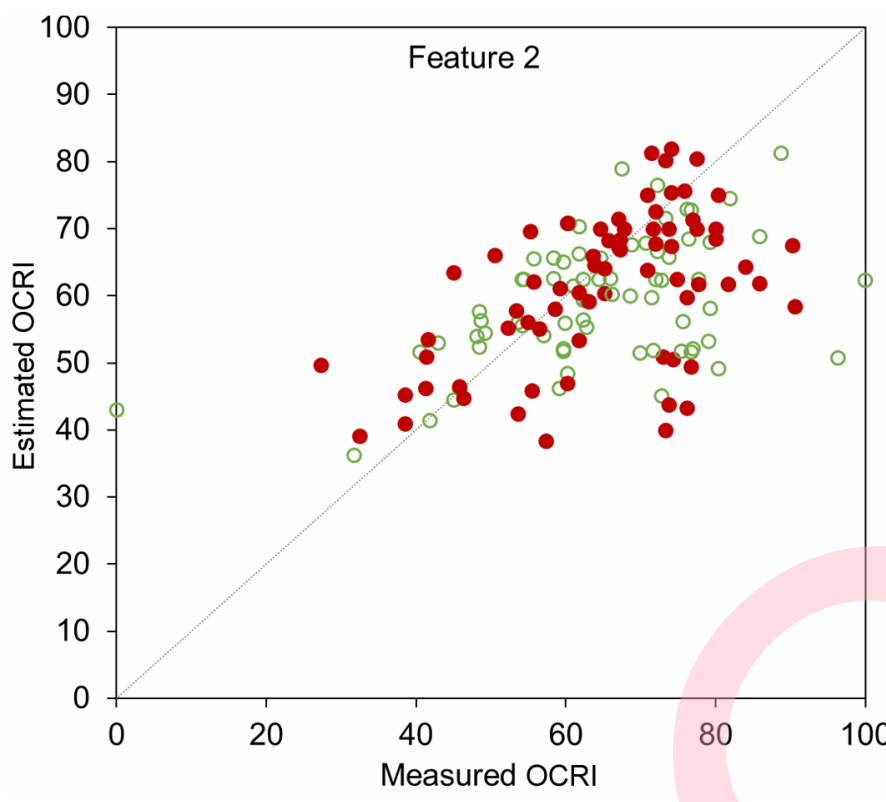

Figure 4.- Representation of the measured OCRI against the estimated OCRI of the neural network proposed for the feature 2, differentiating the white (open green circle) and red wines (solid red circle).

The results of the ANOVA comparing the chemical composition of white wines with OCRI values show a non-significant correlation (Table 1). However, the red wines in this study show a positive and statistically significant correlation between the OCRI and $\mathrm{Cu}$ content $(0.6134, \mathrm{p}=0.0115)$ but no significant correlation with $\mathrm{Fe}$; this result coincides with that reported by Ferreira et al 2015 (Ferreira et al., 2015); and also with volatile acidity $(0.6498, \mathrm{p}=0.0064)$, while there is a statistically significant negative correlation with total acidity $(-0.6344, \mathrm{p}=0.0083)$. For instance, the red wine with the highest OCRI was a red sample (RRW2) with the highest $\mathrm{Cu}$ content $(0.62 \mathrm{mg} / \mathrm{L})$, but relatively low iron content $(1.6 \mathrm{mg} / \mathrm{L})$ and intermediate content total acidity $(4.7 \mathrm{~g} / \mathrm{L})$ and volatile acidity $(0.46 \mathrm{~g} / \mathrm{L})$. The red wine with the lowest OCRI was a red sample (RRW8) with the lowest Fe content $(0.7 \mathrm{mg} / \mathrm{L})$ and highest total acidity $(5.3 \mathrm{~g} / \mathrm{L})$ and a low $\mathrm{Cu}$ content $(0.05 \mathrm{mg} / \mathrm{L})$ and relatively low volatile acidity $(0.37 \mathrm{~g} / \mathrm{L})$. Therefore, it is not enough to discover the chemical properties to define the oxygen consumption rate of the studied wines, but rather the chemical properties of the wines need to be evaluated as a whole.

\section{Conclusions}

In this work, we propose a phenomenological fitting for oxygen consuming kinetics which improves on the widely used exponential method. To our knowledge, this is the first time real white and red wines are shown to have similar kinetics of oxygen consumption. The use of Artificial Neural Networks has turned out to be a valid tool for predicting oxygen consumption rates. Six chemical parameters selected among those commonly used in wineries have been used as inputs, allowing the estimation of the oxygen consumption rate index. A larger set of real wine samples should be considered in order to offer a practical tool to wineries. 


\section{Acknowledgements}

This work was financed by the Ministerio de Ciencia e Innovacion, Ministerio de Economía y Competitividad, the European Regional Development Fund (MINECOFEDER, AGL2014-54602-P) and by the Junta de Castilla y León (VA124U14, VA028U16), Spain. V.F.L. thanks FONDECYT grant 1150725 and University of Valladolid for the Research and Teaching Stay Grant 2016. Thanks to Professor Valentín Pando for his help with the experimental design.

\section{References}

Abramovič, H., Košmerl, T., Poklar Ulrih, N., \& Cigić, B. (2015). Contribution of SO2 to antioxidant potential of white wine. Food Chemistry, 174, 147-153.

Box, G. E. P., \& Behnken, D. W. (1960). Some New Three Level Designs for the Study of Quantitative Variables. Technometrics, 2(4), 455-475.

Calderón, J. F., Alamo-Sanza, M. del, Nevares, I., \& Laurie, F. (2014). The influence of selected winemaking equipment and operations on the concentration of dissolved oxygen in wines. Ciencia E Investigación Agraria, 41(2), 273-280.

Carrascon, V., Fernandez-Zurbano, P., Bueno, M., \& Ferreira, V. (2015). Oxygen Consumption by Red Wines. Part II: Differential Effects on Color and Chemical Composition Caused by Oxygen Taken in Different Sulfur Dioxide-Related Oxidation Contexts. Journal of Agricultural and Food Chemistry, 63(51), 10938-10947.

CEE. (1990). Reglamento No. 2676/90 Métodos de Análisis Comunitarios Aplicables al Sector del Vino. Diario Oficial de las Comunidades Europeas.

Clark, A. C., Prenzler, P. D., \& Scollary, G. R. (2003). The Role of Copper(II) in the Bridging Reactions of (+)-Catechin by Glyoxylic Acid in a Model White Wine. Journal of Agricultural and Food Chemistry, 51(21), 6204-6210.

Costa Martins, R., Monforte, A. R., \& Silva Ferreira, A. (2013). Port wine oxidation management: a multiparametric kinetic approach. Journal of Agricultural and Food Chemistry, 61(22), 5371-9.

Danilewicz, J. C. (2003). Review of Reaction Mechanisms of Oxygen and Proposed Intermediate Reduction Products in Wine: Central Role of Iron and Copper. American Journal of Enology and Viticulture, 54(2), 73-85.

Danilewicz, J. C. (2007). Interaction of Sulfur Dioxide, Polyphenols, and Oxygen in a WineModel System: Central Role of Iron and Copper. American Journal of Enology and Viticulture, 58(1), 53-60.

Danilewicz, J. C. (2014). Role of Tartaric and Malic Acids in Wine Oxidation. Journal of Agricultural and Food Chemistry, 62(22), 5149-5155.

Danilewicz, J. C. (2015). Reaction of Oxygen and Sulfite in Wine. American Journal of Enology and Viticulture, 67(1), 13 LP-17.

Danilewicz, J. C., Seccombe, J. T., \& Whelan, J. (2008). Mechanism of Interaction of Polyphenols, Oxygen, and Sulfur Dioxide in Model Wine and Wine. American Journal of Enology and Viticulture, 59(2), 128-136.

del Alamo-Sanza, M., Pando, V., \& Nevares, I. (2014). Investigation and correction of the interference of ethanol, sugar and phenols on dissolved oxygen measurement in wine. Analytica Chimica Acta, 809, 162-173.

Del Alamo, M., Nevares, I., \& Cárcel, L. M. (2006). Redox potential evolution during red wine aging in alternative systems. Analytica Chimica Acta, 563(1-2), 223-228.

Du Toit, W. ., Lisjak, K., Marais, J., \& Du Toit, M. (2006). The effect of microoxygenation on the phenolic composition, quality and aerobic wine-spoilagemicroorganisms of different South African red wines. South African Journal for Enology and Viticulture, 27(1), 57-67.

du Toit, W. J., Marais, J., Pretorius, I. S., \& du Toit, M. (2006). Oxygen in must and wine: A review. South African Journal for Enology and Viticulture, 27(1), 76-94.

Elias, R. J., Andersen, M. L., Skibsted, L. H., \& Waterhouse, A. L. (2009). Identification of Free Radical Intermediates in Oxidized Wine Using Electron Paramagnetic Resonance 
Spin Trapping. Journal of Agricultural and Food Chemistry, 57(10), 4359-4365.

Elias, R. J., \& Waterhouse, A. L. (2010). Controlling the Fenton Reaction in Wine. Journal of Agricultural and Food Chemistry, 58(3), 1699-1707.

Escudero, A., Asensio, E., Cacho, J., \& Ferreira, V. (2002). Sensory and chemical changes of young white wines stored under oxygen. An assessment of the role played by aldehydes and some other important odorants. Food Chemistry, 77(3), 325-331.

Ferreira, V., Carrascon, V., Bueno, M., Ugliano, M., \& Fernandez-Zurbano, P. (2015). Oxygen Consumption by Red Wines. Part I: Consumption Rates, Relationship with Chemical Composition, and Role of SO2. Journal of Agricultural and Food Chemistry, 63(51), 10928-10937.

Hagan, M. T., \& Menhaj, M. B. (1994). Training Feedforward Networks with the Marquardt Algorithm. IEEE Transactions on Neural Networks, 5(6), 989-993.

Holm Hansen, E., Nissen, P., Sommer, P., Nielsen, J. C., \& Arneborg, N. (2001). The effect of oxygen on the survival of non-Saccharomyces yeasts during mixed culture fermentations of grape juice with Saccharomyces cerevisiae. Journal of Applied Microbiology, 91(3), 541-547.

International Standard Organization. (2012). 5814:2012 Water Quality - Determination of Dissolved Oxygen - Electrochemical Probe Method. ISO 5814:2012. Geneva, Switzerland: International Standard Organization (ISO).

Kilmartin, P. A., \& Zou, H. (2001). The Effect of Electrode Material on the Measured Redox Potential of Red and White Wines. Electroanalysis, 13(16), 1347-1350.

Kondrashov, A., Ševčík, R., Benáková, H., Koštírová, M., \& Štípek, S. (2009). The key role of grape variety for antioxidant capacity of red wines. E-SPEN, the European E-Journal of Clinical Nutrition and Metabolism, 4(1), e41-e46.

Kreitman, G. Y., Danilewicz, J. C., Jeffery, D. W., \& Elias, R. J. (2016). Reaction Mechanisms of Metals with Hydrogen Sulfide and Thiols in Model Wine. Part 2: Iron- and CopperCatalyzed Oxidation. Journal of Agricultural and Food Chemistry, 64(20), 4105-4113.

Kreitman, G. Y., Laurie, V. F., \& Elias, R. J. (2013). Investigation of Ethyl Radical Quenching by Phenolics and Thiols in Model Wine. Journal of Agricultural and Food Chemistry, 61(3), 685-692.

Laurie, V. F., Salazar, S., Campos, M. I., Cáceres-Mella, A., \& Peña-Neira, Á. (2014). Periodic Aeration of Red Wine Compared to Microoxygenation at Production Scale. American Journal of Enology and Viticulture, 65(2), 254-260.

Laurie, V. F., Zúñiga, M. C., Carrasco-Sánchez, V., Santos, L. S., Cañete, Á., Olea-Azar, C., ... Agosin, E. (2012). Reactivity of 3-sulfanyl-1-hexanol and catechol-containing phenolics in vitro. Food Chemistry, 131(4), 1510-1516.

Moutounet, M., \& Mazauric, J.-P. (2001). L'oxygène dissous dans les vins : Les gaz en oenologie. Revue Française D'oenologie, 186, 12-15.

Mulero, J., Pardo, F., \& Zafrilla, P. (2010). Antioxidant activity and phenolic composition of organic and conventional grapes and wines. Journal of Food Composition and Analysis, 23(6), 569-574.

Näykki, T., Jalukse, L., Helm, I., \& Leito, I. (2013). Dissolved Oxygen Concentration Interlaboratory Comparison: What Can We Learn? Water, 5(2), 420-442.

Oliveira, C. M., Barros, A. S., Silva Ferreira, A. C., \& Silva, A. M. S. (2015). Influence of the temperature and oxygen exposure in red Port wine: A kinetic approach. Food Research International, 75, 337-347.

Oliveira, C., Silva Ferreira, A. C., De Freitas, V., \& Silva, A. M. S. (2011). Oxidation mechanisms occurring in wines. Food Research International, 44(5), 1115-1126.

Oliveira, V., Knapic, S., \& Pereira, H. (2012). Natural variability of surface porosity of wine cork stoppers of different commercial classes. Journal International Des Sciences De La Vigne Et Du Vin, 46(4), 331-340.

Palacios Macías, V. M., Caro Pina, I., \& Pérez Rodríguez, L. (2001). Factors Influencing the Oxidation Phenomena of Sherry Wine. American Journal of Enology and Viticulture, 52(2), 151-155. 
Schmidtke, L. M., Clark, A. C., \& Scollary, G. R. (2011). Micro-Oxygenation of Red Wine: Techniques, Applications, and Outcomes. Critical Reviews in Food Science and Nutrition, 51(2), 115-131.

Singleton, V. (1987). Oxygen with phenols and related reactions in musts, wines, and model systems: Observations and practical implications. American Journal of Enology and Viticulture, 38(1), 69-77.

Singleton, V. L., \& Rossi Jr., J. A. (1965). Colorimetry of Total Phenolics with Phosphomolybdic-Phosphotungstic Acid Reagents. American Journal of Enology and Viticulture, 16(3), 144-158.

Vrček, I. V., Bojić, M., Žuntar, I., Mendaš, G., \& Medić-Šarić, M. (2011). Phenol content, antioxidant activity and metal composition of Croatian wines deriving from organically and conventionally grown grapes. Food Chemistry, 124(1), 354-361.

Zúñiga, M. C., Pérez-Roa, R. E., Olea-Azar, C., Laurie, V. F., \& Agosin, E. (2014). Contribution of metals, sulfur-dioxide and phenolic compounds to the antioxidant capacity of Carménère wines. Journal of Food Composition and Analysis, 35(1), 37-43.

\section{Supplementary material}


Table 1.- Box-Behnken factorial design

\begin{tabular}{|c|c|c|c|c|c|c|c|c|c|c|c|c|c|}
\hline TWW & $\operatorname{AD}(\%)$ & $\begin{array}{c}\text { TA } \\
(\mathrm{g} / \mathrm{L})\end{array}$ & $\begin{array}{c}\mathrm{SO} 2 \mathrm{~T} \\
(\mathrm{mg} / \mathrm{L})\end{array}$ & $\begin{array}{c}\mathrm{Cu} \\
(\mathrm{mg} / \mathrm{L})\end{array}$ & $\begin{array}{c}\mathrm{Fe} \\
(\mathrm{mg} / \mathrm{L})\end{array}$ & $\begin{array}{c}\mathrm{TP} \\
(\mathrm{mg} / \mathrm{L}) \\
\end{array}$ & RTW & $\begin{array}{l}\text { AD } \\
(\%)\end{array}$ & $\begin{array}{c}\text { TA } \\
(\mathbf{m g} / \mathbf{L})\end{array}$ & $\begin{array}{c}\mathrm{SO2T} \\
(\mathrm{mg} / \mathrm{L})\end{array}$ & $\begin{array}{c}\mathrm{Cu} \\
(\mathrm{mg} / \mathrm{L})\end{array}$ & $\mathrm{Fe}$ & $\begin{array}{c}\text { TP } \\
(\mathrm{mg} / \mathrm{L})\end{array}$ \\
\hline WTW1 & 12.5 & 6 & 100 & 0.4 & 0.5 & 300 & $\begin{array}{l}\text { RTW1 } \\
\end{array}$ & 14 & 6 & 70 & 0.4 & 0.5 & 3000 \\
\hline WTW2 & 13.5 & 5.25 & 75 & 0.03 & 0.5 & 300 & RTW2 & 15 & 5.25 & 50 & 0.03 & 0.5 & 3000 \\
\hline WTW3 & 12.5 & 5.25 & 75 & 0.4 & 3 & 300 & RTW3 & 14 & 5.25 & 50 & 0.4 & 4 & 3000 \\
\hline WTW4 & 11.5 & 4.5 & 75 & 0.8 & 3 & 300 & RTW4 & 13 & 4.5 & 50 & 0.8 & 4 & 3000 \\
\hline WTW5 & 13.5 & 4.5 & 75 & 0.03 & 3 & 300 & RTW5 & 15 & 4.5 & 50 & 0.03 & 4 & 3000 \\
\hline WTW6 & 12.5 & 6 & 75 & 0.4 & 0.5 & 200 & RTW6 & 14 & 6 & 50 & 0.4 & 0.5 & 2000 \\
\hline WTW7 & 12.5 & 6 & 50 & 0.4 & 0.5 & 300 & RTW7 & 14 & 6 & 30 & 0.4 & 0.5 & 3000 \\
\hline WTW8 & 12.5 & 6 & 50 & 0.4 & 6 & 300 & RTW8 & 14 & 6 & 30 & 0.4 & 8 & 3000 \\
\hline WTW9 & 12.5 & 5.25 & 75 & 0.4 & 3 & 300 & RTW9 & 14 & 5.25 & 50 & 0.4 & 4 & 3000 \\
\hline WTW10 & 12.5 & 6 & 75 & 0.4 & 0.5 & 400 & RTW10 & 14 & 6 & 50 & 0.4 & 0.5 & 4000 \\
\hline WTW11 & 12.5 & 5.25 & 75 & 0.4 & 0.5 & 400 & RTW11 & 14 & 5.25 & 50 & 0.4 & 0.5 & 4000 \\
\hline WTW12 & 11.5 & 5.25 & 75 & 0.03 & 6 & 300 & RTW12 & 13 & 5.25 & 50 & 0.03 & 8 & 3000 \\
\hline WTW13 & 12.5 & 4.5 & 75 & 0.4 & 0.5 & 200 & RTW13 & 14 & 4.5 & 50 & 0.4 & 0.5 & 2000 \\
\hline WTW14 & 12.5 & 4.5 & 75 & 0.4 & 6 & 400 & RTW14 & 14 & 4.5 & 50 & 0.4 & 8 & 4000 \\
\hline WTW15 & 12.5 & 4.5 & 75 & 0.4 & 6 & 200 & RTW15 & 14 & 4.5 & 50 & 0.4 & 8 & 2000 \\
\hline WTW16 & 12.5 & 5.25 & 100 & 0.8 & 3 & 200 & RTW16 & 14 & 5.25 & 70 & 0.8 & 4 & 2000 \\
\hline WTW17 & 13.5 & 5.25 & 75 & 0.8 & 6 & 300 & RTW17 & 15 & 5.25 & 50 & 0.8 & 8 & 3000 \\
\hline WTW18 & 12.5 & 6 & 75 & 0.4 & 6 & 400 & RTW18 & 14 & 6 & 50 & 0.4 & 8 & 4000 \\
\hline WTW19 & 13.5 & 5.25 & 100 & 0.4 & 3 & 400 & RTW19 & 15 & 5.25 & 70 & 0.4 & 4 & 4000 \\
\hline WTW20 & 11.5 & 4.5 & 75 & 0.03 & 3 & 300 & RTW20 & 13 & 4.5 & 50 & 0.03 & 4 & 3000 \\
\hline WTW21 & 12.5 & 5.25 & 75 & 0.4 & 3 & 300 & RTW21 & 14 & 5.25 & 50 & 0.4 & 4 & 3000 \\
\hline WTW22 & 12.5 & 5.25 & 100 & 0.03 & 3 & 400 & RTW22 & 14 & 5.25 & 70 & 0.03 & 4 & 4000 \\
\hline WTW23 & 11.5 & 5.25 & 100 & 0.4 & 3 & 200 & RTW23 & 13 & 5.25 & 70 & 0.4 & 4 & 2000 \\
\hline WTW24 & 13.5 & 6 & 75 & 0.8 & 3 & 300 & RTW24 & 15 & 6 & 50 & 0.8 & 4 & 3000 \\
\hline WTW25 & 11.5 & 6 & 75 & 0.03 & 3 & 300 & RTW25 & 13 & 6 & 50 & 0.03 & 4 & 3000 \\
\hline WTW26 & 12.5 & 5.25 & 75 & 0.4 & 3 & 300 & RTW26 & 14 & 5.25 & 50 & 0.4 & 4 & 3000 \\
\hline WTW27 & 11.5 & 5.25 & 50 & 0.4 & 3 & 200 & RTW27 & 13 & 5.25 & 30 & 0.4 & 4 & 2000 \\
\hline WTW28 & 12.5 & 5.25 & 75 & 0.03 & 3 & 200 & RTW28 & 14 & 5.25 & 70 & 0.03 & 4 & 2000 \\
\hline WTW29 & 11.5 & 5.25 & 75 & 0.4 & 3 & 400 & RTW29 & 13 & 5.25 & 70 & 0.4 & 4 & 4000 \\
\hline WTW30 & 12.5 & 6 & 75 & 0.4 & 6 & 200 & RTW30 & 14 & 6 & 50 & 0.4 & 8 & 2000 \\
\hline WTW31 & 12.5 & 4.5 & 50 & 0.4 & 0.5 & 300 & RTW31 & 14 & 4.5 & 30 & 0.4 & 0.5 & 3000 \\
\hline WTW32 & 13.5 & 5.25 & 100 & 0.4 & 3 & 200 & RTW32 & 15 & 5.25 & 70 & 0.4 & 4 & 2000 \\
\hline WTW33 & 13.5 & 5.25 & 75 & 0.03 & 6 & 300 & RTW33 & 15 & 5.25 & 50 & 0.03 & 8 & 3000 \\
\hline WTW34 & 11.5 & 6 & 75 & 0.8 & 3 & 300 & RTW34 & 13 & 6 & 50 & 0.8 & 4 & 3000 \\
\hline WTW35 & 12.5 & 5.25 & 75 & 0.4 & 3 & 300 & RTW35 & 14 & 5.25 & 50 & 0.4 & 4 & 3000 \\
\hline WTW36 & 12.5 & 4.5 & 100 & 0.4 & 0.5 & 300 & RTW36 & 14 & 4.5 & 70 & 0.4 & 0.5 & 3000 \\
\hline WTW37 & 12.5 & 5.25 & 75 & 0.4 & 3 & 300 & RTW37 & 14 & 5.25 & 50 & 0.4 & 4 & 3000 \\
\hline WTW38 & 12.5 & 5.25 & 100 & 0.8 & 3 & 400 & RTW38 & 14 & 5.25 & 70 & 0.8 & 4 & 4000 \\
\hline WTW39 & 13.5 & 5.25 & 50 & 0.4 & 3 & 400 & RTW39 & 15 & 5.25 & 30 & 0.4 & 4 & 4000 \\
\hline WTW40 & 12.5 & 5.25 & 50 & 0.03 & 3 & 200 & RTW40 & 14 & 5.25 & 30 & 0.03 & 4 & 2000 \\
\hline WTW41 & 13.5 & 5.25 & 75 & 0.8 & 0.5 & 300 & RTW41 & 15 & 5.25 & 50 & 0.8 & 0.5 & 3000 \\
\hline WTW42 & 13.5 & 4.5 & 75 & 0.8 & 3 & 300 & RTW42 & 15 & 4.5 & 50 & 0.8 & 4 & 3000 \\
\hline WTW43 & 13.5 & 5.25 & 50 & 0.4 & 3 & 200 & RTW43 & 15 & 5.25 & 30 & 0.4 & 4 & 2000 \\
\hline WTW44 & 11.5 & 5.25 & 75 & 0.8 & 0.5 & 300 & RTW44 & 13 & 5.25 & 50 & 0.8 & 0.5 & 3000 \\
\hline WTW45 & 12.5 & 6 & 100 & 0.4 & 6 & 300 & RTW45 & 14 & 6 & 70 & 0.4 & 8 & 3000 \\
\hline WTW46 & 11.5 & 5.25 & 75 & 0.8 & 6 & 300 & RTW46 & 13 & 5.25 & 0 & 0.8 & 8 & 3000 \\
\hline WTW47 & 11.5 & 5.25 & 50 & 0.4 & 3 & 400 & RTW47 & 13 & 5.25 & 30 & 0.4 & 4 & 4000 \\
\hline WTW48 & 12.5 & 4.5 & 50 & 0.4 & 6 & 300 & RTW48 & 14 & 4.5 & 30 & 0.4 & 8 & 3000 \\
\hline WTW49 & 13.5 & 6 & 75 & 0.03 & 3 & 300 & RTW49 & 15 & 6 & 50 & 0.03 & 4 & 3000 \\
\hline WTW50 & 12.5 & 5.25 & 50 & 0.03 & 3 & 400 & RTW50 & 14 & 5.25 & 30 & 0.03 & 4 & 4000 \\
\hline WTW51 & 12.5 & 5.25 & 50 & 0.8 & 3 & 200 & RTW51 & 14 & 5.25 & 30 & 0.8 & 4 & 2000 \\
\hline WTW52 & 12.5 & 5.25 & 50 & 0.8 & 3 & 400 & RTW52 & 14 & 5.25 & 30 & 0.8 & 4 & 4000 \\
\hline WTW53 & 12.5 & 4.5 & 100 & 0.4 & 6 & 300 & RTW53 & 14 & 4.5 & 70 & 0.4 & 8 & 3000 \\
\hline WTW54 & 11.5 & 5.25 & 75 & 0.03 & 0.5 & 300 & RTW54 & 13 & 5.25 & 50 & 0.03 & 0.5 & 3000 \\
\hline
\end{tabular}

White training wines $(W T W)$ and red training wines $(R T W)$ 
Table 2.- Correlations between the parameters of the adjustment equations (A) exponential equation and (B) phenomenological equation and the chemical parameters.

\begin{tabular}{lcccccccc}
\hline & \multicolumn{2}{c}{ Parameter (A) } & \multicolumn{3}{c}{$a$} & \multicolumn{2}{c}{ Parameter (B) } & \multicolumn{2}{c}{$c$} \\
& \multicolumn{2}{c}{$K$} & \multicolumn{2}{c}{$a$} & \multicolumn{2}{c}{$c$} \\
& WRW & RRW & WRW & RRW & WRW & RRW & WRW & RRW \\
\cline { 2 - 9 } $\mathrm{AD}(\%)$ & 0.4099 & 0.1483 & 0.2558 & 0.128 & 0.2682 & 0.1269 & 0.3577 & 0.1662 \\
$\mathrm{TA}(\mathrm{g} / \mathrm{L})$ & 0.2881 & -0.3213 & -0.1728 & -0.4228 & -0.1538 & -0.4254 & 0.4094 & -0.1282 \\
$\mathrm{SO} 2 \mathrm{~T}(\mathrm{mg} / \mathrm{L})$ & 0.2726 & -0.1845 & 0.2526 & -0.1827 & 0.2629 & -0.1848 & 0.1774 & -0.1822 \\
$\mathrm{Fe}(\mathrm{mg} / \mathrm{L})$ & 0.0351 & -0.1188 & -0.1668 & -0.0763 & -0.1684 & -0.0785 & 0.1364 & -0.2706 \\
$\mathrm{Cu}(\mathrm{mg} / \mathrm{L})$ & $0.7816^{* * *}$ & $0.7185^{* *}$ & 0.4545 & $0.7544 * * *$ & 0.4794 & $0.7542 * * *$ & $0.5922^{*}$ & 0.2150 \\
$\mathrm{TP}(\mathrm{mg} / \mathrm{L})$ & -0.0834 & -0.1672 & 0.2421 & -0.173 & 0.2377 & -0.1752 & -0.1548 & -0.1821 \\
\hline
\end{tabular}

Significative plevel: $*=p<0.05, * * 0.05<p<0.01, * * * p<0.001$

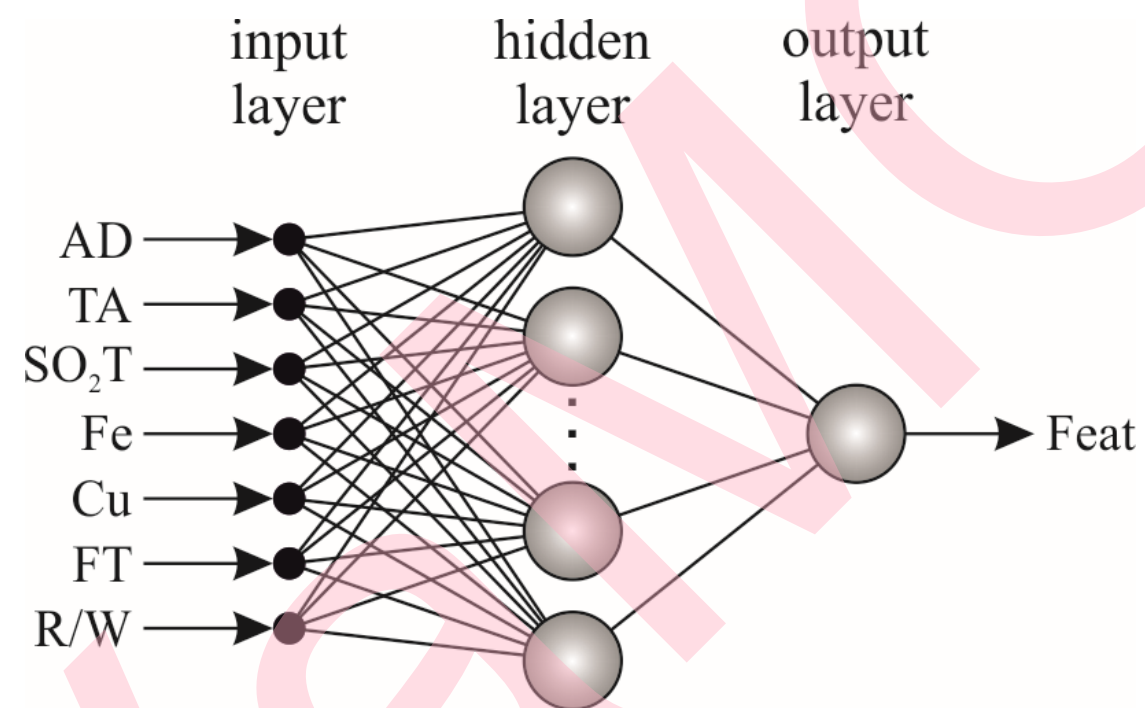

Figure 1.- Multilayer perceptron ANN used in the article, with seven inputs and an output.

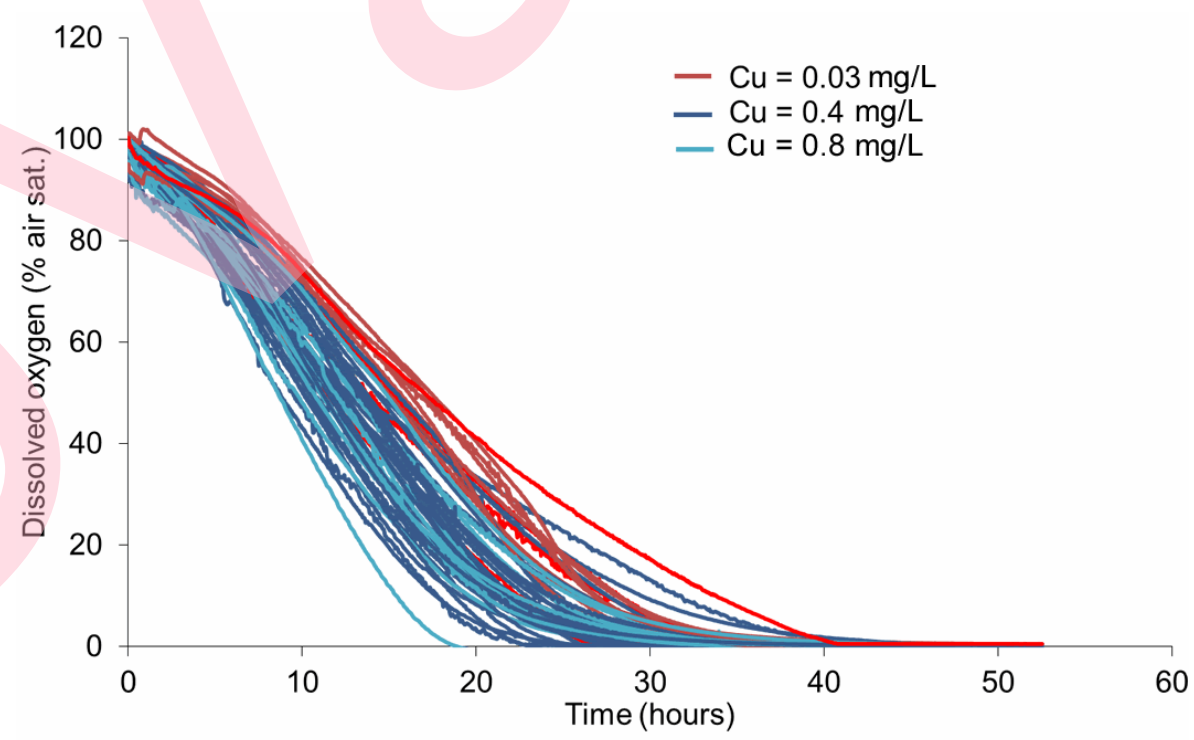

Figure 2.- Red Training Wines with the three different $\mathrm{Cu}$ content levels. 